\title{
Quantitative Research and Characterization of the Loess Microstructure in the Bai Lu Tableland, Shaanxi Province, China
}

\author{
Longsheng Deng $\mathbb{D}^{1,2,3}$ Wen Fan $\mathbb{D}^{1,2,3}$ Shaopeng Liu, ${ }^{1}$ Yupeng Chang, ${ }^{1}$ Yan Dai, \\ and Yubo $\mathrm{Li}^{4}$ \\ ${ }^{1}$ School of Geological Engineering and Geomatics, Chang'an University, Xi'an 710054, China \\ ${ }^{2}$ Key Laboratory of Western China Mineral Resources and Geological Engineering, Xi'an 710054, China \\ ${ }^{3}$ Key Laboratory of Mine Geological Hazards Mechanism and Control, Xi'an, China \\ ${ }^{4}$ China Railway First Survey and Design Institute Group Co., Ltd., Xi'an, China \\ Correspondence should be addressed to Longsheng Deng; dlsh@chd.edu.cn and Wen Fan; fanwen@chd.edu.cn
}

Received 30 October 2019; Revised 27 April 2020; Accepted 1 May 2020; Published 10 June 2020

Academic Editor: Rafael J. Bergillos

Copyright (C) 2020 Longsheng Deng et al. This is an open access article distributed under the Creative Commons Attribution License, which permits unrestricted use, distribution, and reproduction in any medium, provided the original work is properly cited.

\begin{abstract}
Loess is a special geotechnical material with strong structural properties, and the microstructural characteristics of loess significantly influence its macroscopic physical features, mechanical properties, and catastrophic behavior. In this paper, serial samples were extracted from the continuous loess and paleosol strata of the Bai Lu tableland; with these samples, the optical microscopy-based serial sectioning method was adopted to study the quantitative characterization and variation in the loess microstructure. Threedimensional characteristics and quantitative parameters of the particles, pores, and throats of the loess were obtained. The results indicate that the volume, Eq-Radius, and major-minor axis ratio of the loess particles satisfy third-order, third-order, and secondorder Gaussian distributions, respectively. The Eq-Radius of the loess pores and throats satisfies a first-order Gaussian distribution, and the throat channel length satisfies a gamma distribution. With increasing stratum depth, the particles become more flattened, the throat radii become larger and the pore channels become slenderer. The variation in fitting parameters and the correlations between the macrophysical and mechanical properties of loess were then explored. The study of the microstructure of loess contributes to a better understanding of the catastrophic behavior of loess and the physical mechanism of geologic hazards in this area.
\end{abstract}

\section{Introduction}

Loess generally shows a high strength when dry, but under conditions of soaking, the skeleton of loess weakens rapidly, which would result in the collapse of loess, settlement of loess ground, and instability of a loess slope [1-3]. As a special geotechnical material, loess is known for its strong structure, water sensitivity, and seismic vulnerability, among which the water sensitivity and seismic vulnerability essentially originate from its structural properties. Microstructural characteristics are the most dominant factors controlling the structural properties of loess and can directly influence the engineering properties and macroscopic mechanical behavior of loess $[4,5]$. As a granular material, the deformation and failure of loess begins with shear deformation and slippage among particles; on the other hand, the mechanical properties of loess are dominated by its microstructure $[4,6,7]$. The microstructure of loess mainly consisted of pores, particles, and connections, which control the contact system and force chains in the loess and then dominate the macrophysical and mechanical properties of loess [8]. The study of the microstructure of loess contributes to a better understanding of the catastrophic behavior and physical mechanism of loess geologic hazards.

Scientists and engineers have long noticed the importance of microstructure for the determination of loess engineering properties $[9,10]$, and considerable efforts have been made to explore the microstructure of loess. These studies mainly focus on the following aspects: (1) investigation of loess microstructural characteristics and variations 
among different regions and geological ages, (2) classification of loess microstructure and determination of the corresponding microstructural parameters, (3) evolution of loess microstructure under specific conditions, and (4) microscopic mechanism of typical loess geologic hazards.

Due to the variation in material provenance, sedimentary geological environment, and history, the microstructural characteristics and parameters vary from loess to loess. The structural characteristics of Malan loess in the midstream area of the Yellow River, which were studied using the oil immersion method, were described earlier in terms of the loess microstructure $[9,11]$. Subsequently, increasingly more studies have been presented. Loess samples from various regions, depths, and geological ages were extracted to study the pore sizes, particle characteristics, and cementations, as well as the types of loess microstructures [2, 12-18]. Mercury intrusion porosimetry (MIP) and scanning electron microscopy (SEM) are the most widely adopted techniques in such studies, and the investigations have mainly concentrated on the determination of the plane morphology, two-dimensional characteristics of the loess pores and particles, and corresponding microstructural parameters [19].

Determination of loess microstructure types could provide more insight into the catastrophic characteristics and mechanical behavior of loess. On the basis of microscopic observations, a widely used classification of pores in loess was proposed according to pore size. Four types of pores, macropores, mesopores, fine pores, and micropores, were proposed, and the division thresholds were pore diameters of $0.032 \mathrm{~mm}, 0.008 \mathrm{~mm}$, and $0.002 \mathrm{~mm}$, respectively $[20,21]$. Loess microstructure was divided into 12 categories by Gao $[22,23]$, mainly considering the forms of grains, modes of arrangement, and types of connection, and divided into 6 categories by Lei, considering the cementation strengths and pore types $[20,21]$. The influence of microstructure types on the stability of loess has been properly studied [24], and many conceptual microstructure models have been proposed to explore the mechanism of loess deformation and failure [14, 25-27], which has a great significance for the assessment of loess engineering.

The engineering properties of loess are fundamentally controlled by their microstructure. Many scholars have devoted their work to exploring the relationship between the microstructural parameters and mechanical properties of loess, and a combination of microtests and macrophysicalmechanical experiments has been carried out [5, 28-32]. The achievements demonstrated that the variation in loess strength is directly related to the changes in microstructure and that cementation bonds play an important role in the strength and deformation behavior of loess [30]. These studies paved the way for the establishment of disaster theory of loess on multiple scales of analysis.

The importance of loess microstructure for the understanding of loess collapse and corresponding geohazards has been demonstrated by many recent efforts [3, 33-39]. Based on microstructure tests and analyses, the formation and development of loess microstructures during collapse were divided into five stages [1]. Many conceptual models have been proposed to elucidate the origin of loess collapsibility [25]. The contribution of the microstructure to the strength of compacted loess after soaking was explored [40], and the relationship of the collapse potential versus the microstructural parameters of the loess was qualitatively studied [41]. The relationship between loess microstructure and seismic subsidence and the relationship between microstructure and shear strength under freezing conditions were studied [42-45]. However, despite these efforts, the current understanding of the cause of collapsibility and the underlying mechanisms controlling loess collapse behavior remain controversial or incomplete.

Notably, the research quality and image resolution have been improving gradually with the development of new observation apparatuses and processing technologies, and the achievements reflect the shift from qualitative analysis to quantitative research. Most of these achievements are concentrated around the characterization of two-dimensional (2D) morphology, and very few researchers have studied the three-dimensional (3D) microstructural characteristics of loess. To date, optical and electron microscopy, nuclear magnetic resonance (NMR), and X-ray computed tomography (CT) are the most commonly used techniques used to obtain microscopic images of soil, among which optical and electron microscopy are generally used to obtain two-dimensional images [46-48]. NMR is more suitable for detecting pores in materials filled with water, and highenergy X-ray CT scanning can be used to obtain images with higher resolutions but is expensive and not easily accessible to most researchers in geotechnical engineering. With the advent of serial sectioning, microscopy-based image analysis can be used to create 3D microstructures [49]. It is feasible to obtain the 3D microstructure of loess by combining optical microscope scanning, serial sectioning, and $3 \mathrm{D}$ image reconstruction. Although the method of optical microscopybased serial sectioning has the disadvantage of being timeconsuming and laborious, it is inexpensive and easy to follow yet produces large, high-resolution area images, which can capture both short-range features (particles) and long-range features (localized zones) to enable a more comprehensive characterization of the soil microstructure.

The Bai Lu tableland is located in the southern Wei He Basin, Shaanxi Province, China, and is covered by a great thickness of loess with continuous loess-paleosol interbedded strata. Due to the approximate flat geography, the typical microstructural characteristics of aeolian loess in the tableland were preserved well. In this paper, Di Zhai village was chosen as the research site. Data collection and field investigation were performed to determine the geological conditions of the site. Engineering drilling was carried out to explore the loess and paleosol strata. Serial samples from various loess and paleosol strata were extracted. Field and laboratory tests were conducted to obtain the physical and mechanical parameters of the loess. The optical microscopybased serial sectioning method was adopted; the experiment method included sample preparation, observation, image processing, structure reconstruction, and quantitative index analysis. The characteristics of the loess particles and pores and the microstructural parameters were systematically 
studied. This work could provide a scientific basis for the study of loess catastrophic mechanics theory and the construction of projects in this area.

\section{Experimental Method and Scheme}

The Bai Lu tableland is located in the southern Wei He Basin adjacent to the northern Qin Ling Mountains, which is a strip terrain oriented southeast-northwest and divides the Ba and Chan rivers. According to the geological tectonic background and evolution history, the Bai Lu tableland was formed on river terraces with aeolian loess covers and was affected by fault activity and fluviatile erosion. The geologic conditions of the study area are presented in Figure 1. According to the strata data, the loess in the Bai Lu tableland has been depositing since the early Pleistocene, accumulating a thickness of approximately $65-126 \mathrm{~m}$ of a continuous loess-paleosol strata sequence. The Bai Lu tableland is a suitable site for studying the variation in microstructural characteristics of the loess-paleosol sequence.

An $80 \mathrm{~m}$ deep geological borehole was drilled in Di Zhai village, from which 8 layers of loess and 7 layers of paleosol were explored. The depth and thickness of every layer are presented in Figure 1. Samples were extracted from every layer, with which the physical parameters were tested and are presented in Table 1.

The optical microscopy-based serial sectioning method was adopted to study the 3D microstructure of the loess. The experiment and image reconstruction process mainly involved the following steps. (1) Sample preparation: a subcubic sample with a side length less than $1.0 \mathrm{~cm}$ was extracted from the loess sample and then saturated in a vacuum environment using a special liquid. The liquid is a mixture of epoxy resin, acetone, ethane diamine, and dibutyl phthalate, with constant volume ratios of $200 \mathrm{ml}, 100 \mathrm{ml}, 4 \mathrm{ml}$, and $2 \mathrm{ml}$. Acetone has a low consistency and can be easily volatilized; the mixed liquid was diluted and could easily infiltrate into the pores of the loess sample. Ethane diamine and dibutyl phthalate accelerate the solidification process and improve the hardness of the sample. Finally, the sample was prepared via secondary casting for polishing and observation. (2) Image capture: the sample was polished to obtain a smooth plane using Multiprep equipment, with which the polishing process could be controlled to a precision of $0.1 \mu \mathrm{m}$. The planar image of the sample with the resolution of $0.4 \mu \mathrm{m} /$ pixel was observed using a Leica DM6000M microscope. The sample was then repolished to remove approximately $2 \mu \mathrm{m}$, which was controlled using the vertical displacement laser monitor and the polishing duration. A series of $2 \mathrm{D}$ images with a spacing of $2 \mu \mathrm{m}$ were then obtained. (3) Three-dimensional (3D) structure reconstruction: all the slices were aligned and converted to extract the particles and pores, adopting the appropriate threshold via the changes of gray scale. Generally, the point of inflection for the colormap of gray intensity is selected as the threshold value. The $2 \mathrm{D}$ images were calibrated, and the 3D particle and pore morphologies were then reconstructed using Avizo software. (4) Quantitative analysis: the microstructural characteristics, parameters, and variations of various layers of loess were then analyzed using the statistical indexes of particles, throats, and pores. The experiment and image reconstruction processes are presented in Figure 2. Since the undisturbed samples of strata L7 and L8 were not extracted successfully, the microstructure study mainly focused in strata L1-S6.

\section{Three-Dimensional Quantitative Characteristics of Loess Particles}

The morphological characteristics of loess particles could be depicted by adopting the parameters volume $(V)$, Eq-Radius $(\mathrm{Eq}-\mathrm{R}=\sqrt[3]{(6 \times V) / \pi})$, orientation, and major-minor axis ratio, among which the orientation was described by adopting the angles phi and theta, and the major-minor axis ratio was defined as $W / L$. The definitions of the characteristic parameters of a loess particle are presented in Figure 3.

Figures 4(a) and 4(b) present the distribution of quantitative probability versus the corresponding volume of the loess particle, in which the test data, fitting curve, and cumulative probability curve of loess L1 and paleosol S1 are presented, respectively. According to the figures, the experimental data could be fitted well by applying the thirdorder Gaussian distribution function. The fitting function can be expressed as formula (1), in which $x_{P-V}$ represents the particle volume and $\alpha 1, \alpha 2, \alpha 3, b 1, b 2, b 3, c 1, c 2$, and $c 3$ are the fitting parameters. According to the fitting condition, the correlation coefficient of fitting is approximately equal to 1.0. For loess L1, $60 \%$ of the loess particles have a volume smaller than $35 \mu \mathrm{m}^{3}, 70 \%$ of the particles are smaller than $65 \mu \mathrm{m}^{3}$, and $80 \%$ of the particles are smaller than $215 \mu \mathrm{m}^{3}$; for paleosol S1, the thresholds of $60 \%, 70 \%$, and $80 \%$ correspond to $70 \mu \mathrm{m}^{3}, 150 \mu \mathrm{m}^{3}$, and $415 \mu \mathrm{m}^{3}$, respectively. Consequently, it is obvious that the loess L1 of the Bai Lu tableland is finer than the paleosol S1.

$$
\begin{aligned}
f\left(x_{(P-V)}\right)= & \alpha 1 \times e^{-1 \times\left(\left(x_{(P-V)}-b 1\right) / c 1\right)^{2}}+\alpha 2 \times e^{-1 \times\left(\left(x_{(P-V)}-b 2\right) / c 2\right)^{2}} \\
& +\alpha 3 \times e^{-1 \times\left(\left(x_{(P-V)}-b 3\right) / c 3\right)^{2}} .
\end{aligned}
$$

Figure 4(c) presents a comparison of the fitting curves of various layers of loess and paleosol, indicating that the deeper layer generally involves a larger proportion of small particles, while layer L3 shows a finer particle characteristic. Figure 4(d) shows the variation in the fitting parameters of the loess and paleosol layers. Although the fitting parameter $\alpha 1$ varies from layer to layer, the value of $\alpha 1$ for the paleosol is generally greater than that of the adjacent loess layer. The values of $b$ and $c$ tend to increase with increasing depth.

Figures 5(a) and 5(b) show the distribution characteristics of particle Eq-Radius for L1 and S1, and the experimental data also satisfy the third-order Gaussian distribution well. Figure 5(c) presents the variation in the fitting curves for various loess and paleosol layers. The distribution of the curves depicted that finer particles are generally enriched in the upper layers except L3. Figure 5(d) gives the variation in fitting parameters, which shows that the values of the parameters $b 3$ and $c 3$ generally decrease with the increase in depth. 


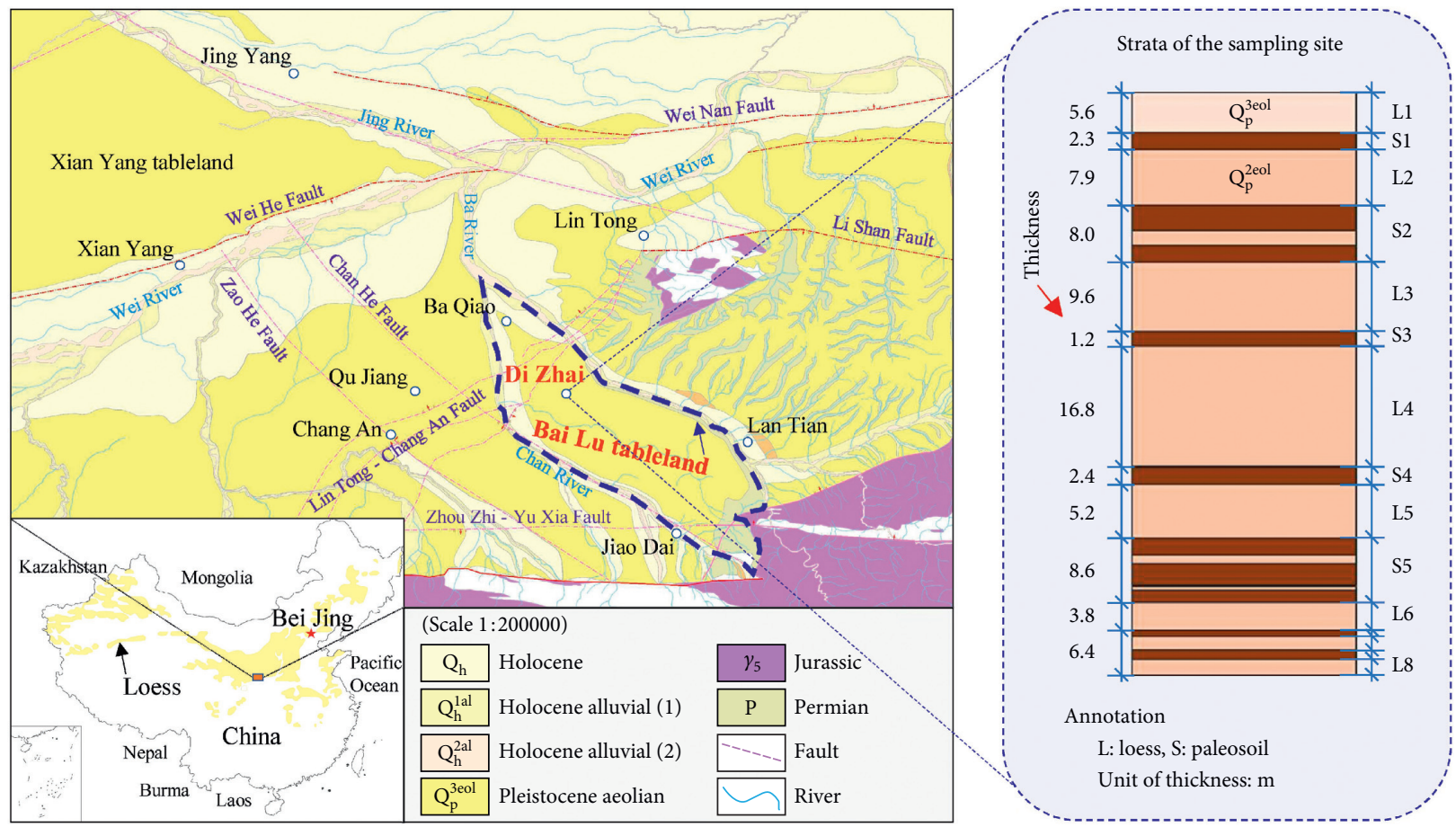

FIgURE 1: Location and geological condition of the study area.

Table 1: Physical parameters of the experimental samples.

\begin{tabular}{lcccccccc}
\hline Stratum & $\begin{array}{c}\text { Depth } d \\
(\mathrm{~m})\end{array}$ & $\begin{array}{c}\text { Thickness } h \\
(\mathrm{~m})\end{array}$ & $\begin{array}{c}\text { Unit mass } \gamma \\
\left(\mathrm{g} / \mathrm{cm}^{3}\right)\end{array}$ & $\begin{array}{c}\text { Water } \\
\text { content } w(\%)\end{array}$ & $\begin{array}{c}\text { Liquid limit } \\
\text { LL }(\%)\end{array}$ & $\begin{array}{c}\text { Plastic limit } \\
P L(\%)\end{array}$ & $\begin{array}{c}\text { Permeability } \\
\text { coefficient } k(\mathrm{~m} / \mathrm{s})\end{array}$ & $\begin{array}{c}\text { Shear wave } \\
\text { velocity } V_{\mathrm{s}}(\mathrm{m} / \mathrm{s})\end{array}$ \\
\hline L1 & 5.6 & 5.6 & 1.81 & 19.4 & 32.0 & 23.7 & $6.12 \times 10^{-5}$ \\
S1 & 7.9 & 2.3 & 1.72 & 22.6 & 31.0 & 22.1 & $5.71 \times 10^{-5}$ & 222.9 \\
L2 & 15.8 & 7.9 & 1.74 & 25.8 & 34.5 & 22.6 & $4.17 \times 10^{-5}$ & 296.7 \\
S2 & 23.8 & 8.0 & 1.78 & 24.3 & 32.7 & 25.3 & $2.71 \times 10^{-5}$ & 416.6 \\
L3 & 33.4 & 9.6 & 1.83 & 26.1 & 30.7 & 20.3 & $3.54 \times 10^{-5}$ & 464.2 \\
S3 & 34.6 & 1.2 & 1.82 & 27.4 & 29.8 & 20.5 & $3.05 \times 10^{-5}$ & 404.5 \\
L4 & 51.4 & 16.8 & 1.80 & 23.7 & 29.5 & 20.7 & $4.72 \times 10^{-5}$ & 504.8 \\
S4 & 53.8 & 2.4 & 1.84 & 23.9 & 29.1 & 21.2 & $2.72 \times 10^{-5}$ & 534.5 \\
L5 & 61.2 & 5.2 & 1.87 & 24.4 & 31.1 & 19.0 & $1.52 \times 10^{-5}$ & 605.8 \\
S5 & 69.8 & 8.6 & 1.79 & 23.3 & 34.1 & 21.4 & $1.27 \times 10^{-5}$ & 757.3 \\
L6 & 73.6 & 3.8 & 1.85 & 22.1 & 29.6 & 21.9 & $1.18 \times 10^{-5}$ & 685.3 \\
S6 & 74.5 & 0.9 & 1.83 & 21.2 & 30.1 & 19.8 & $1.06 \times 10^{-5}$ & 616.3 \\
L7 & 76.4 & 1.9 & 1.82 & 22.4 & 31.2 & 20.1 & $2.92 \times 10^{-5}$ & 660.4 \\
S7 & 77.7 & 1.3 & 1.81 & 23.7 & 32.0 & 20.2 & $2.77 \times 10^{-5}$ & 729.1 \\
L8 & 80.0 & 2.3 & 1.86 & 24.0 & 33.8 & 21.9 & $3.31 \times 10^{-5}$ \\
\hline
\end{tabular}

Figures 6(a) and 6(b) show the distributions of the major-minor axis ratio for loess particles from L1 and S1; these distributions exactly satisfied the second-order Gaussian distribution with a correlation coefficient up to 0.98 . The probability density function in the distribution can be represented by adopting formula (2), where $x_{(A-R)}$ represents the major-minor axis ratio of the loess particles and $\alpha 1, \alpha 2, b 1, b 2, c 1$, and $c 2$ are the fitting parameters. According to the figures, the parameters $\alpha 1, \alpha 2, b 1, b 2, c 1$, and $c 2$ are regressed by applying the least squares method and are determined to be $0.1062,011139,1.837,2.334,0.337$, and 0.6536 for loess L1 and 0.1283, 0.05716, 1.902, 2.599, 0.4602 , and 0.8863 for paleosol S1. Figure 6(c) presents the variation in fitting curves for various loess layers and paleosol layers. The ratios of the major-minor axis length fall in the range of 1.0 to 4.0 for layers $\mathrm{L} 1, \mathrm{~S} 1, \mathrm{~L} 2, \mathrm{~S} 2$, and $\mathrm{L} 4$, the range of 1.0 to 6.0 for layers L5 and S5, and the range of 1.0 to 8.0 for L6 and S6. Consequently, with increasing strata depth, loess particles generally become increasingly flattened.

$$
f\left(x_{(A-R)}\right)=\alpha 1 \times e^{-1 \times\left(\left(x_{(A-R)}-b 1\right) / c 1\right)^{2}}+\alpha 2 \times e^{-1 \times\left(\left(x_{(A-R)}-b 2\right) / c 2\right)^{2}} .
$$

Figures 7(a) and 7(b) show the distribution of the probability density of loess particle quantity versus the corresponding 


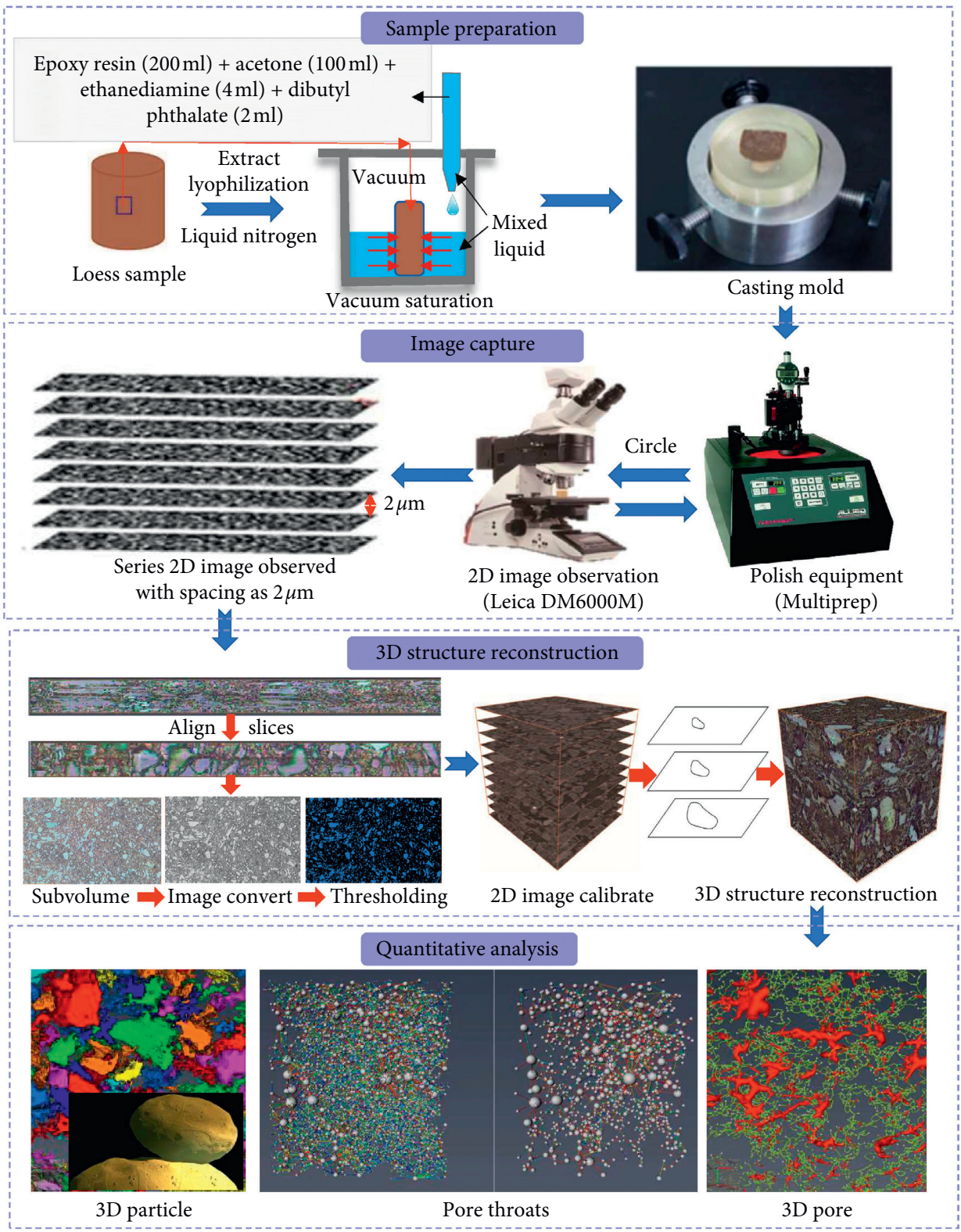

FIGURE 2: The experiment and image reconstruction process.

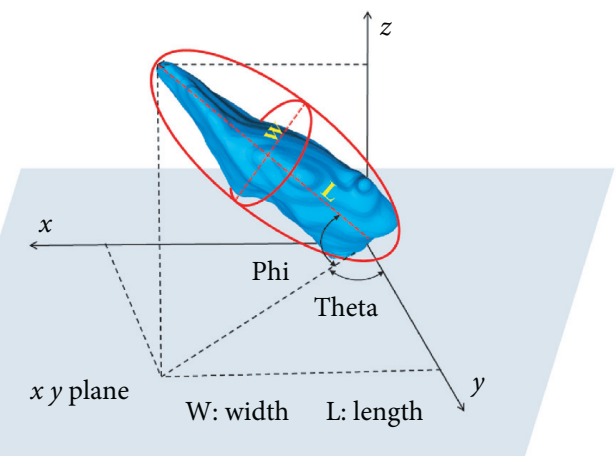

FIGURE 3: Definition of characteristic parameters for loess particles.

value of loess particle orientation. The values of phi mainly fall in the ranges of $0-30^{\circ}$ and $85-90^{\circ}$, which indicates that most of the loess particles were deposited with a gentle inclination and near-vertical orientation. According to Figure 7(a), the value of phi for the upper layer of soil is generally smaller when $0^{\circ}<$ phi $<30^{\circ}$ and larger when $85^{\circ}<$ phi $<90^{\circ}$, which indicates that particles in the deeper layers of loess were more prone to be deposited horizontally. According to Figure 7(b), all the curves increase sharply near the angle theta $=90^{\circ}$, which indicates that the loess deposited with a predominantly eastward orientation, and the directionality characteristics are more obvious for the soil of the upper layer.

\section{Three-Dimensional Quantitative Characteristics of Loess Voids}

The characteristics of loess voids are one of the most dominant factors controlling loess microstructure. The morphological features, size distribution, and connectivity 


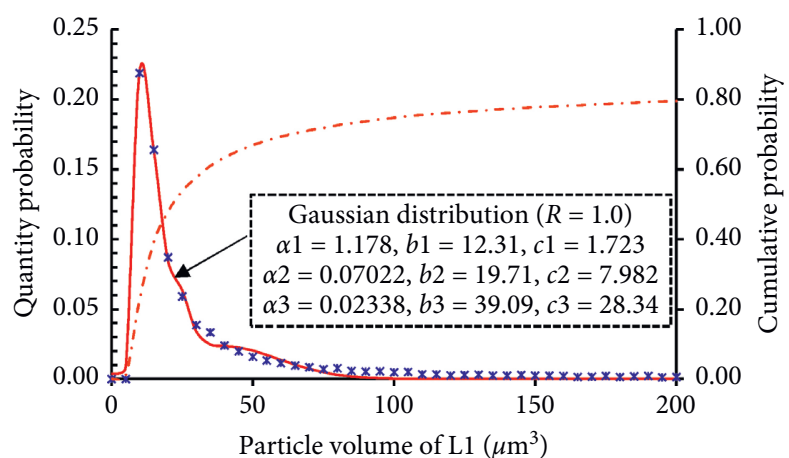

_- Quantity probability fitting curve
* Quantity probability of the experiment data
..- Cumulative probability curve

(a)

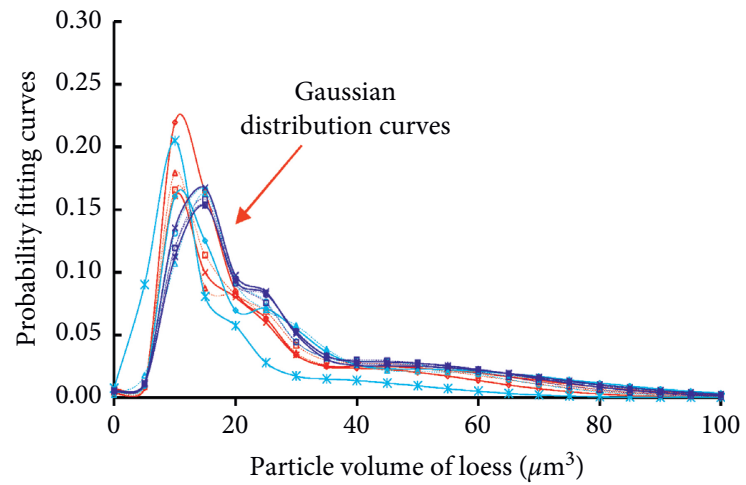

\begin{tabular}{|c|c|c|}
\hline$\multimap \mathrm{L} 1$ & $\longrightarrow$ L & $\ldots$ S3 \\
\hline$\rightarrow$ L2 & $\rightarrow-\mathrm{L}$ & $\cdots \mathrm{S} 4$ \\
\hline$\rightarrow$ L3 & $\cdots \bowtie S$ & $\ldots$. . S5 \\
\hline$\because \mathrm{L} 4$ & $\ldots \mathrm{S}$ & \\
\hline
\end{tabular}

(c)

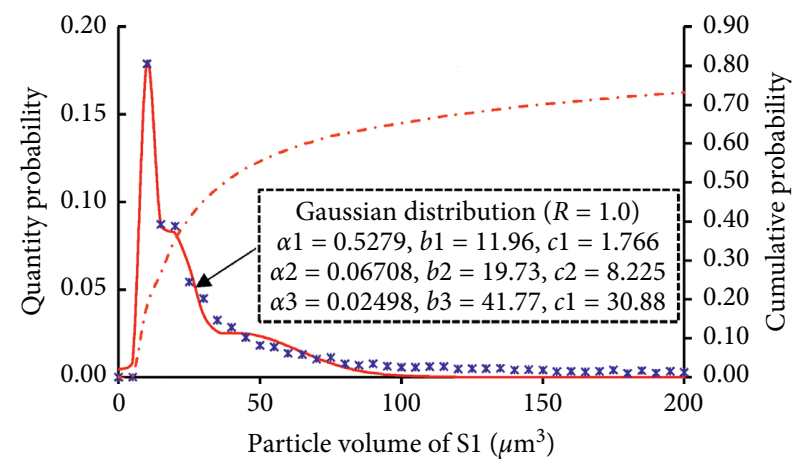

_ Quantity probability fitting curve

* Quantity probability of the experiment data

-..- Cumulative probability curve

(b)

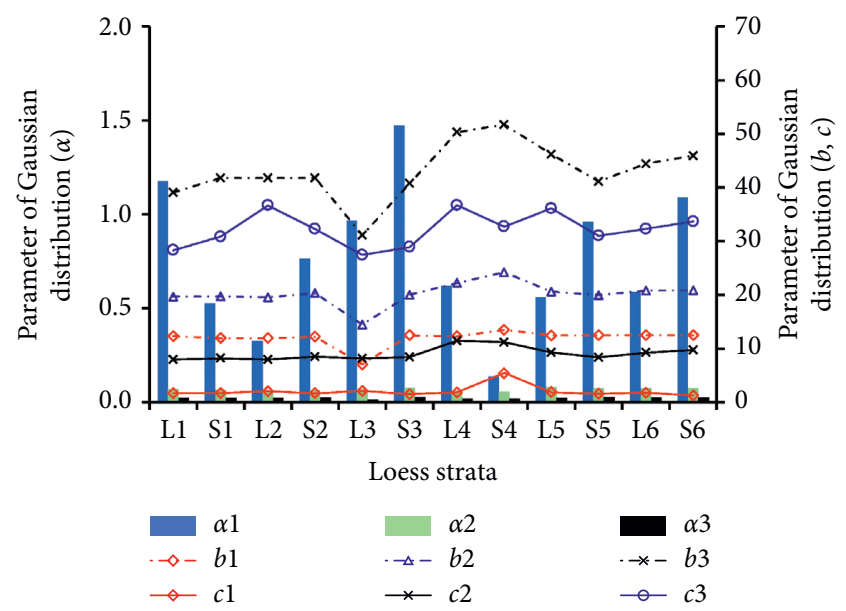

(d)

Figure 4: Distribution characteristics of particle volume: (a) L1; (b) S1; (c) comparison of fitting curves for various layers; (d) variation in fitting parameters.

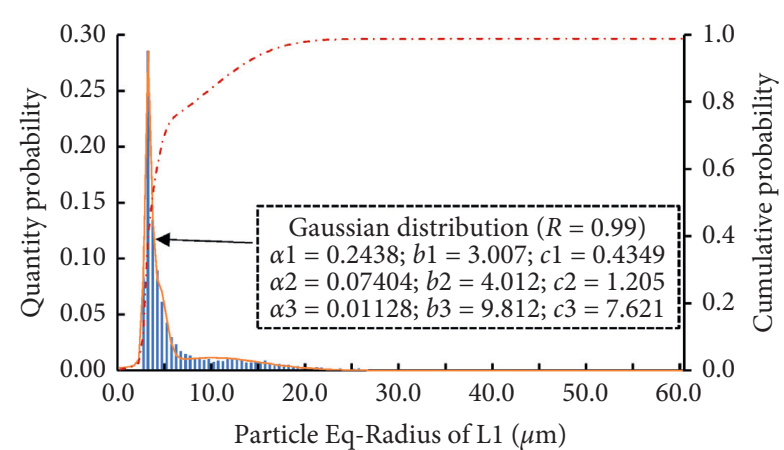

Quantity probability of the experiment data Quantity probability of fitting curve

-.- Cumulative probability curve

(a)

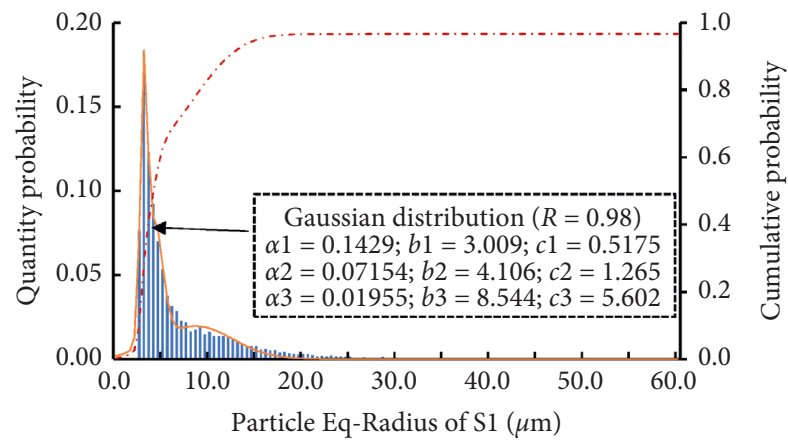

Quantity probability of the experiment data Quantity probability of fitting curve

...- Cumulative probability curve

(b)

FIgURE 5: Continued. 


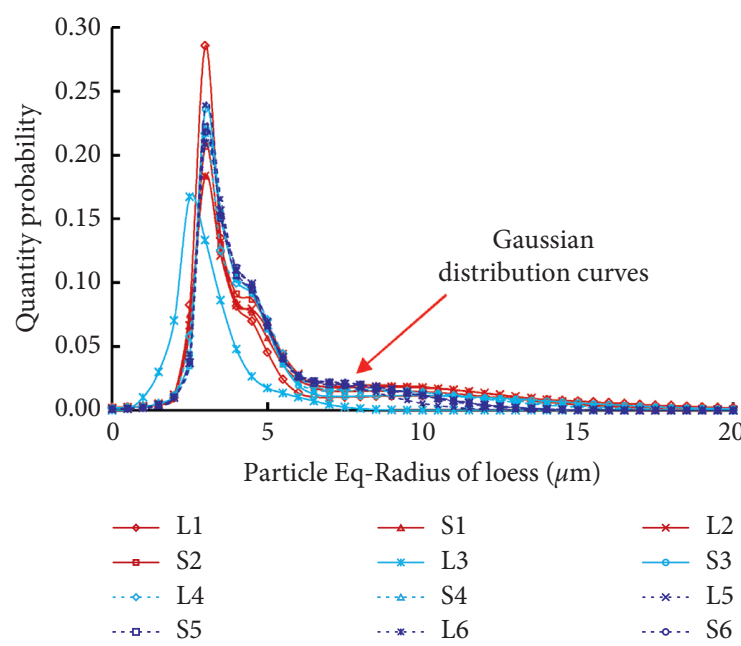

(c)

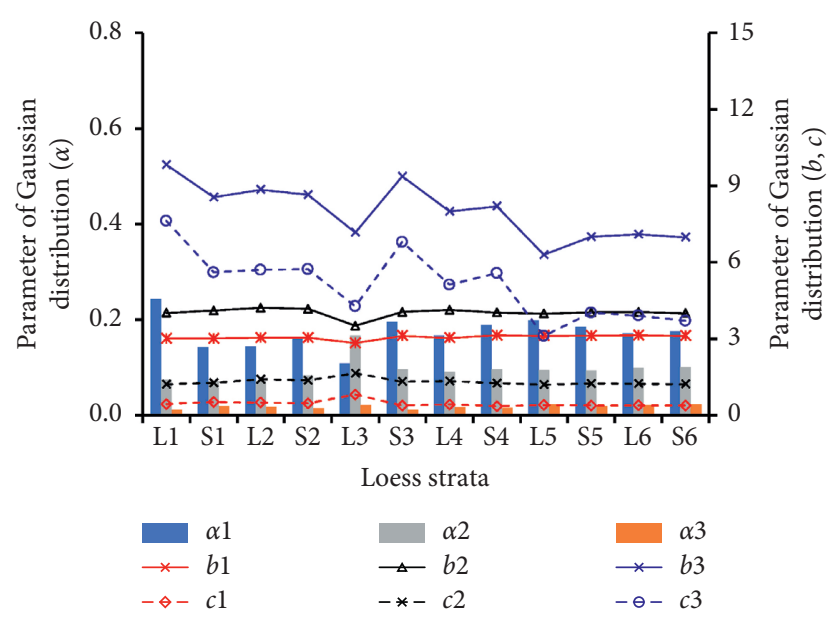

(d)

FiguRE 5: Distribution characteristics of Eq-Radius: (a) L1; (b) S1; (c) comparison of fitting curves of various layers; (d) variation in fitting parameters.

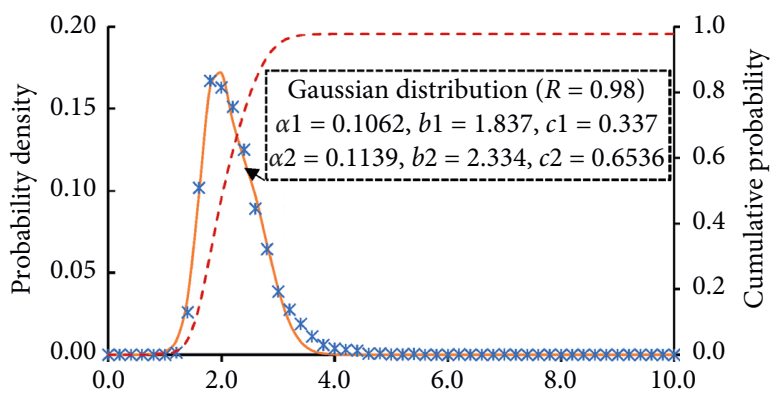

Ratio of major-minor axis length for loess particle of $\mathrm{L} 1$

- Probability density of fitting curve

* Probability density data of experiment

--- Cumulative probability curve

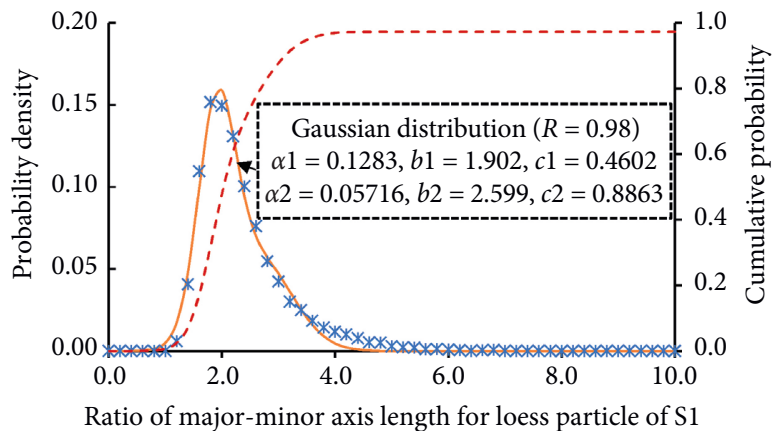

_- Probability density of fitting curve

* Probability density data of experiment

--- Cumulative probability curve

(a)

(b)

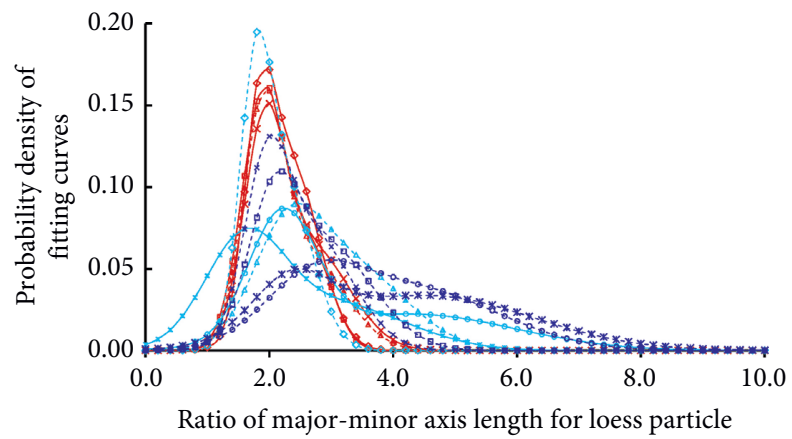

\begin{tabular}{|c|c|c|}
\hline$\because \mathrm{L} 1$ & $\ldots * \ldots$ L5 & $\because \mathrm{S} 3$ \\
\hline * L2 & ..*.. L6 & S4 \\
\hline$\rightarrow$ L3 & $\ldots \ldots \mathrm{S} 1$ & S5 \\
\hline$\ldots \infty \mathrm{L} 4$ & $\rightarrow \mathrm{S} 2$ & $\infty$ \\
\hline
\end{tabular}

(c)

FIGURE 6: Distribution characteristics of the major-minor axis ratio of loess particles: (a) L1; (b) S1; (c) variation in fitting curves for various layers of loess and paleosol. 


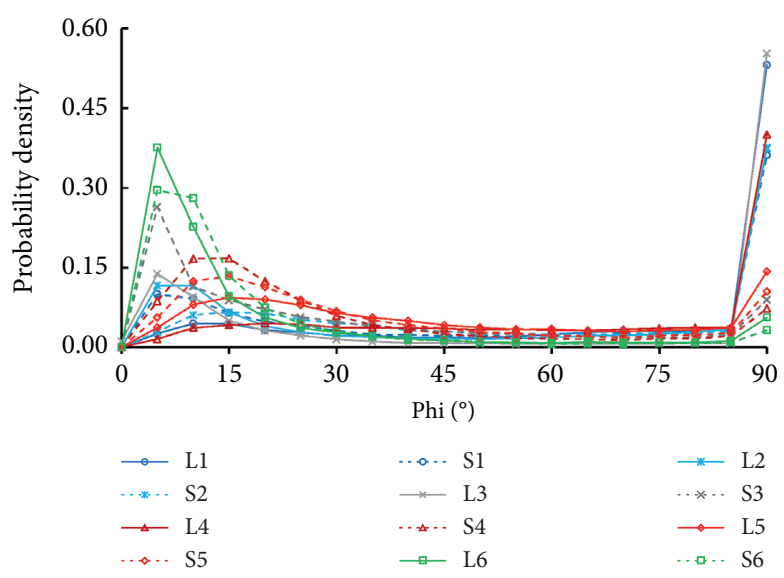

(a)

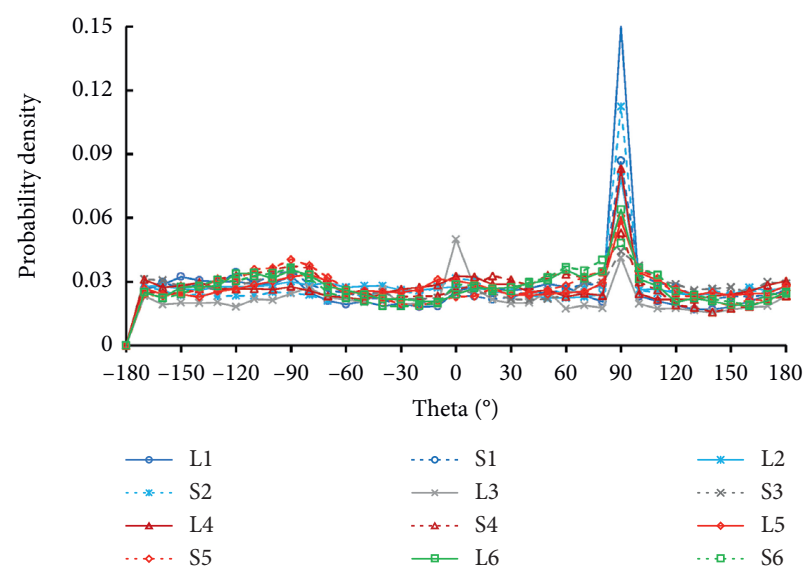

(b)

Figure 7: Orientation characteristics of loess particles: (a) phi; (b) theta.

of voids control the structural, physical, and mechanical properties of loess, as well as its collapsibility, seismic subsidence, and other disaster-related behaviors. Based on the variation and influence of void morphology, we defined throats and pores to depict the void characteristics of loess quantitatively. The throat is defined as a narrow passage through loess pores and connects adjacent pores. The pores in loess could be generalized as a sphere with equal volume, with which the Eq-Radius of the pore was defined as the radius of the sphere, and the throat channel length was defined as the distance between adjacent pore centers. The definitions of the loess void characteristic parameters are presented in Figure 8, in which the chromatic aberrations are due to the visual effect induced by the shadow of threedimensional pores.

According to the experimental results, we extracted voids from images to build a 3D pore network, and the network was separated into many pores by throats. The distribution characteristics of the throat dimension generally directly dominated the connectivity and permeability of loess. The dimension of the throat could be described by adopting the parameter throat Eq-Radius, which was defined as the radius of a circle with equal area. The distribution of throat Eq-Radius in the loess is presented in Figure 9. The relationship of throat Eq-Radius and the corresponding quantity probability density satisfied a first-order Gaussian distribution well. The probability density function can be expressed as formula (3), in which $x_{(T-R)}$ represents the throat Eq-Radius and $\alpha 1, b 1$, and $c 1$ are the fitting parameters. Figures 9(a) and 9(b) show a comparison of the fitting curves versus the experimental data of layers L1 and S1, depicting that the parameters $\alpha 1, b 1$, and $c 1$ are 0.07191 , 3.677, and 4.166, respectively, for loess L1 and $0.08427,3.836$ and 3.4, respectively, for paleosol S1, and that the correlation coefficient $R$ is close to 1.0 in both cases.

$$
f\left(x_{(T-R)}\right)=\alpha 1 \times e^{-1 \times\left(\left(x_{(T-R)}-b 1\right) / c 1\right)^{2}} .
$$

Figure 9(c) gives the distribution characteristics of throat Eq-Radius of various layers. The figure depicts that the

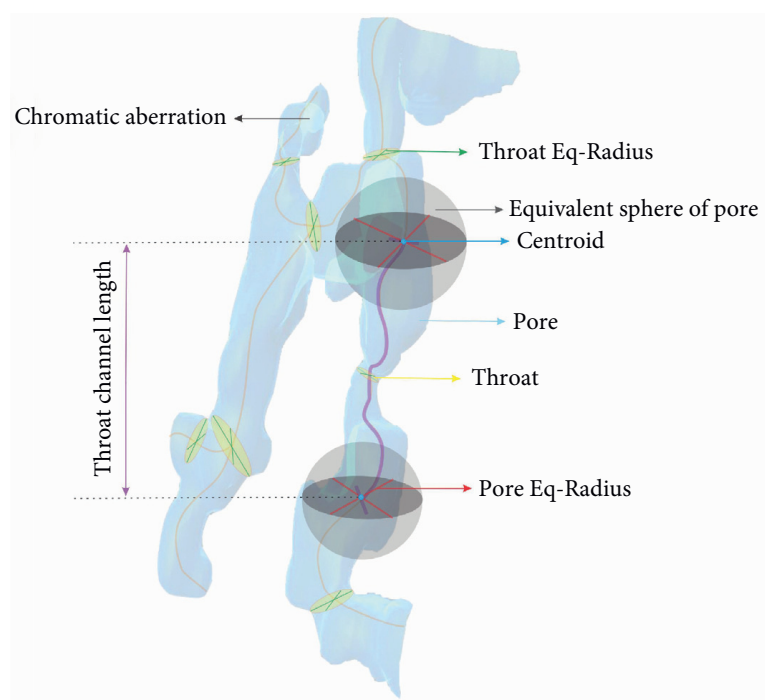

FIGURE 8: Definition of the characteristic parameters of loess voids.

values of throat Eq-Radius are less than $12.5 \mu \mathrm{m}, 11.0 \mu \mathrm{m}$, $13.0 \mu \mathrm{m}, 15.0 \mu \mathrm{m}, 12.0 \mu \mathrm{m}, 14.0 \mu \mathrm{m}, 16.0 \mu \mathrm{m}, 18.0 \mu \mathrm{m}$, $19.0 \mu \mathrm{m}, 20.0 \mu \mathrm{m}, 21.0 \mu \mathrm{m}$, and $22.0 \mu \mathrm{m}$ for L1 to S6, respectively, and that the maximum throat Eq-Radius generally increases gradually with increasing stratum depth. According to the shape of the fitting curves, the curve of a deeper stratum tends to be wider, and the curve of a shallow stratum falls into a relatively tight bound, which indicates that the loess at a great depth has large pore throats. Figure 9(d) represents the variation in fitting parameters for various layers of soil, which depicted that the parameter $\alpha 1$ decreases with increasing stratum depth and that the parameters $b 1$ and $c 1$ show a contrary characteristic.

According to the definition, the throat channel length represents the distribution of the average pore length in the loess and is one of the most important structural parameters that can reflect the uniqueness of loess. The distribution of throat channel length versus the probability density is given in Figure 10, among which Figures 10(a) and 10(b) depict 


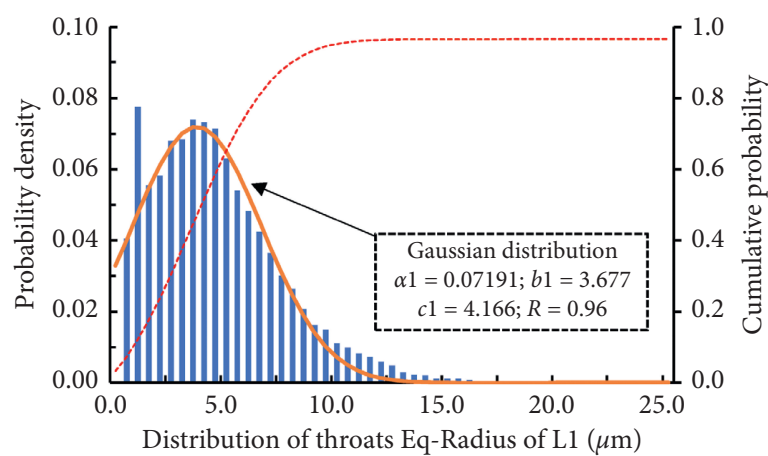

Distribution of throats Eq-Radius of L1 $(\mu \mathrm{m})$

Probability density data of experiment

— Probability density of fitting curve

- - - Cumulative probability curve

(a)

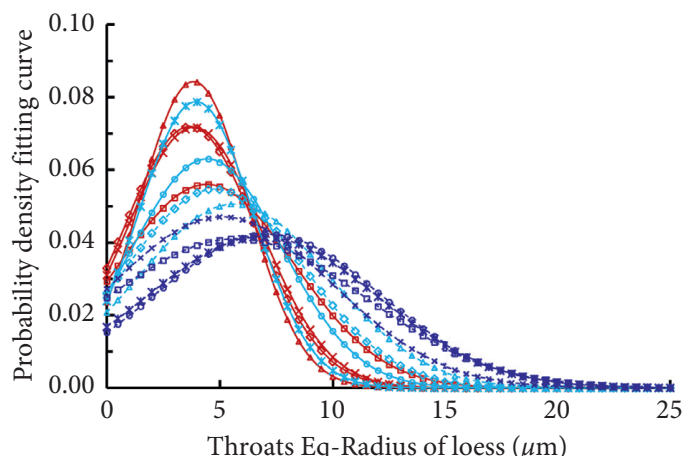

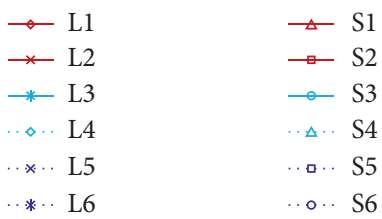

(c)

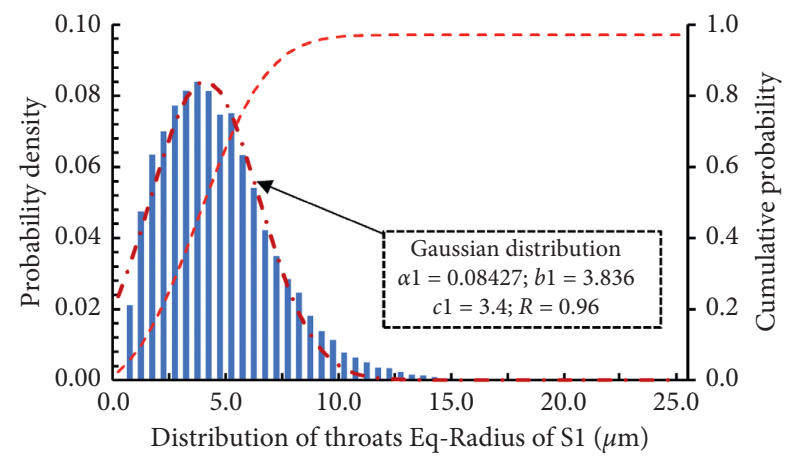

Probability density data of experiment

- .- Probability density of fitting curve

- - - Cumulative probability curve

(b)

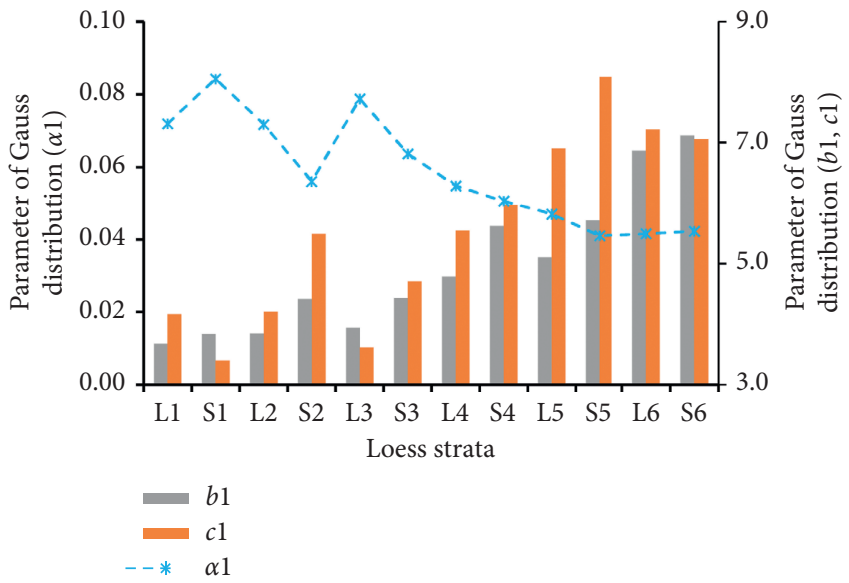

(d)

FIGURE 9: Eq-Radius of loess throats: (a) probability density versus throat Eq-Radius of L1; (b) probability density versus Eq-Radius of S1; (c) distribution characteristics of Eq-Radius for various layers; (d) variation in fitting parameters for various layers of soil.

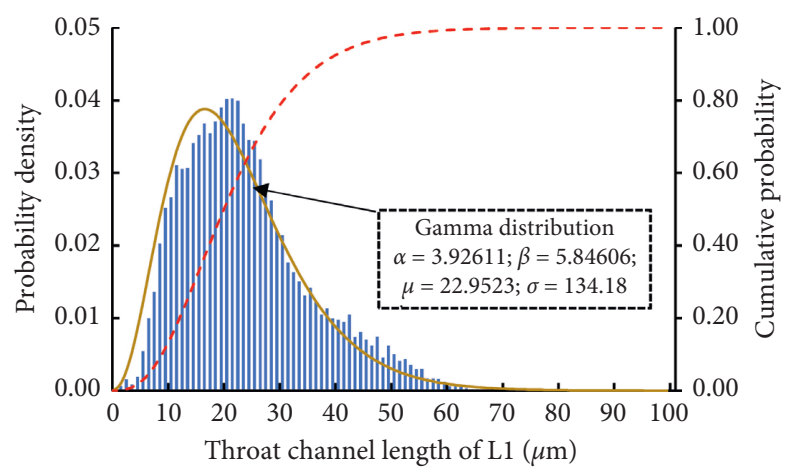

Probability density data of experiment

Probability density of fitting curve

- Cumulative probability curve

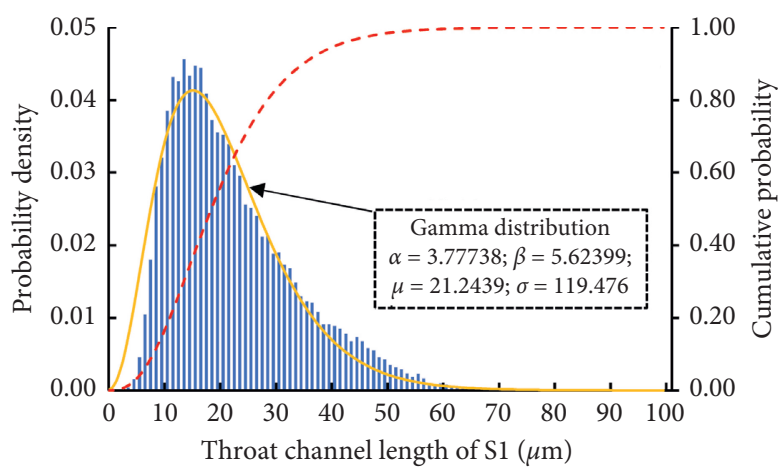

Probability density data of experiment

Probability density of fitting curve

- - - Cumulative probability curve

Figure 10: Continued. 


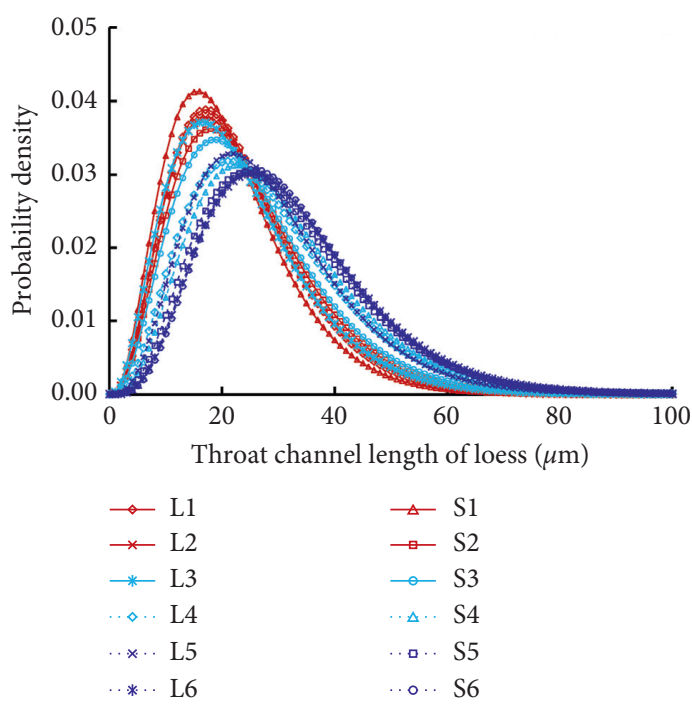

(c)

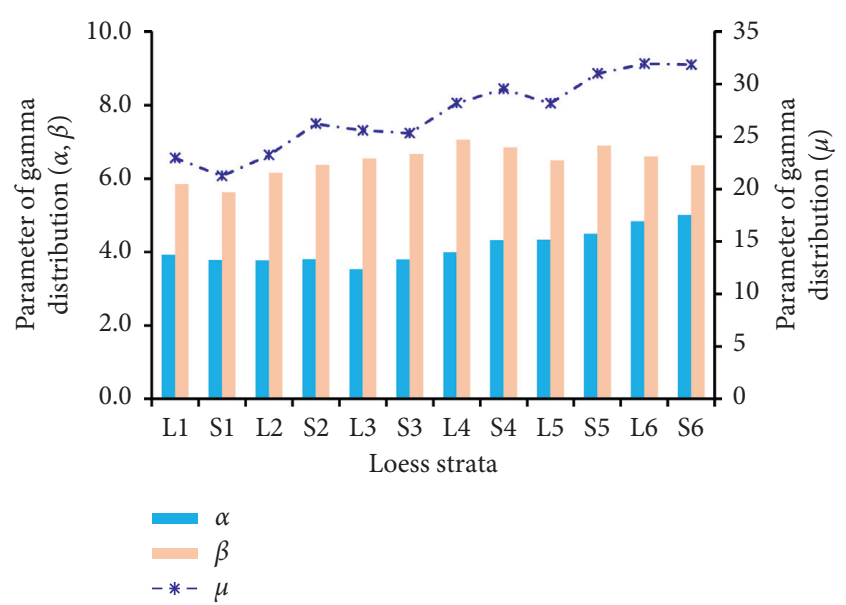

(d)

FIGURE 10: Distribution characteristics of throat channel length: (a) probability density versus channel length of L1; (b) probability density versus channel length of S1; (c) distribution characteristics of channel length for various layers; (d) variation in fitting parameters for various layers of loess.

the comparison of the experimental data and fitting curves of the loess L1 and paleosol S1, respectively. According to the figures, the distribution of throat channel length satisfies the gamma function well. The density function of the gamma distribution can be expressed as follows:

$$
f\left(x_{(T-L)}\right)=\frac{\beta^{\alpha}}{\Gamma(\alpha)} x_{(T-L)}^{(\alpha-1)} e^{-\beta x_{(T-L)}}, \quad x_{(T-L)}>0,
$$

where $x_{(T-L)}$ represents the throat channel length, $\alpha$ is a shape parameter, and $\beta$ is a scale parameter. The $\Gamma(\alpha)$ function is a generalization of a factorial on a real number. The mean value $\mu$ and variance $\sigma$ of the gamma distribution are given by the following formula:

$$
\left\{\begin{array}{l}
\mu=\frac{\alpha}{\beta}, \\
\sigma^{2}=\frac{\alpha}{\beta^{2}} .
\end{array}\right.
$$

The fitting parameters are determined by adopting the least squares method. According to the results, the parameters $\alpha, \beta, \mu$, and $\sigma$ are, respectively, determined to be $3.92611,5.85606,22.9523$, and 134.18 for loess L1 and 3.77738, 5.62399, 21.2439, and 119.467 for paleosol S1.

Figure 10(c) shows the distribution of channel length for various loess and paleosol layers. The curve of the upper layer generally shows a narrower and higher coverage area, as well as a larger peak with a smaller abscissa, which indicates that the pore channel becomes slenderer with increasing stratum depth. Figure $10(\mathrm{~d})$ presents the variation in fitting parameters for various loess strata. According to the figure, the parameters $\alpha$, $\beta$, and $\mu$ increase gradually with increasing stratum depth.

Similar to the determination of the quantitative microstructural parameters for throats, those for pore size could be described by adopting the parameter Eq-Radius of a sphere with an equal volume. Figure 11 gives the distribution characteristics of the pore Eq-Radius for the loess. The comparison of experimental data and fitting curves is presented in Figures 11(a) and 11(b), which shows that the relationship of pore Eq-Radius and probability density also satisfies the first-order Gaussian distribution well. The parameters $\alpha 1, b 1$, and $c 1$ could be regressed by adopting the least squares method and are, respectively, given as 0.1015 , 6.256, and 5.689 for loess L1 and $0.1532,6.71$, and 3.587 for paleosol S1. The corresponding correlation coefficient $R$ results are high. Figure 11(c) shows the distribution characteristics of the pore Eq-Radius for various layers, and Figure 11(d) gives the variation in the fitting parameters for various layers of loess and paleosol. The variations in the fitting curves and parameters for the pore size are similar to those for the throat.

\section{Discussion}

The correlation of the physical parameters (such as unit mass, water content, liquid limit, plastic limit, permeability coefficient, and shear wave velocity) and fitting parameters of the distribution function of the particles, pores, and throats of the loess was studied. The values of the permeability coefficient and shear wave velocity have obvious correlations with the fitting parameters of the loess pores and throats. The relationship between the physical properties and the fitting parameters is presented in Figure 12. According to the figures, the fitting parameters $b 1$ and $c 1$ of the Eq-Radius of the throats and pores and the fitting parameters of throat channel length decrease linearly with the increase in permeability coefficient and increase with the increase in shear wave velocity; meanwhile, the fitting parameter $\alpha 1$ of the Eq-Radius of the throats and pores shows 


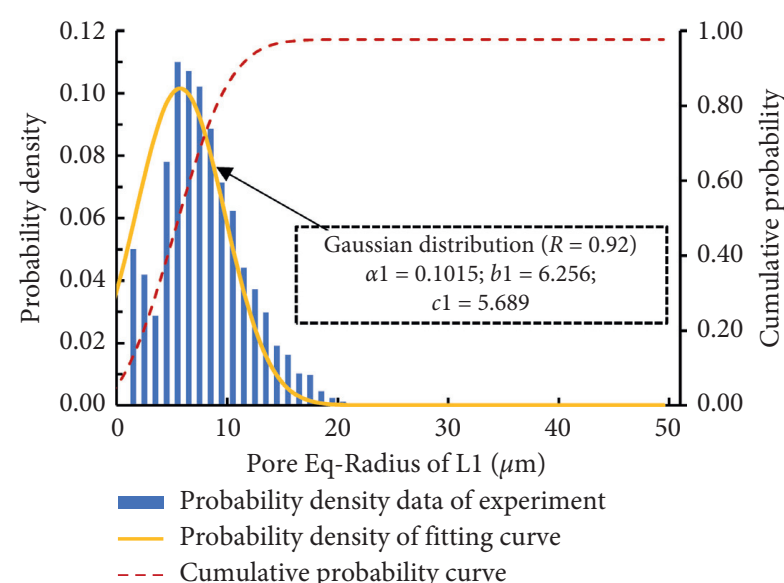

(a)

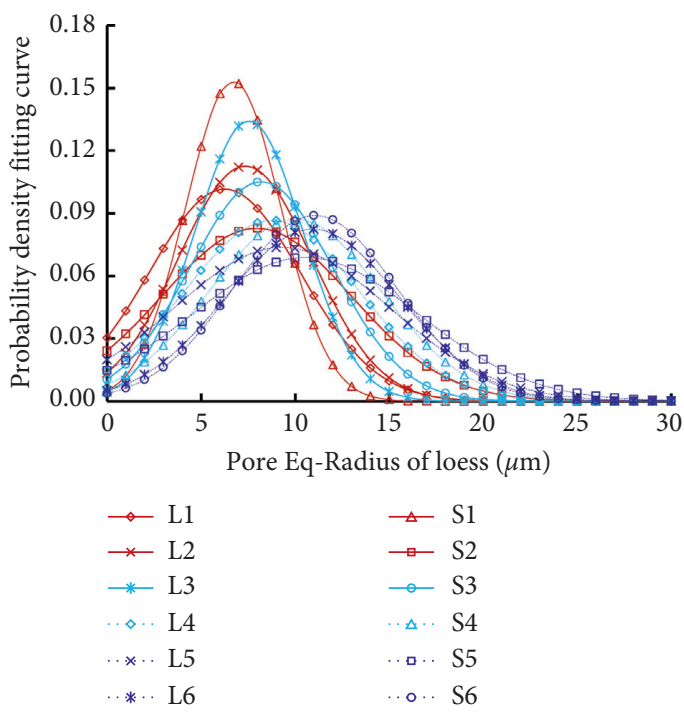

(c)

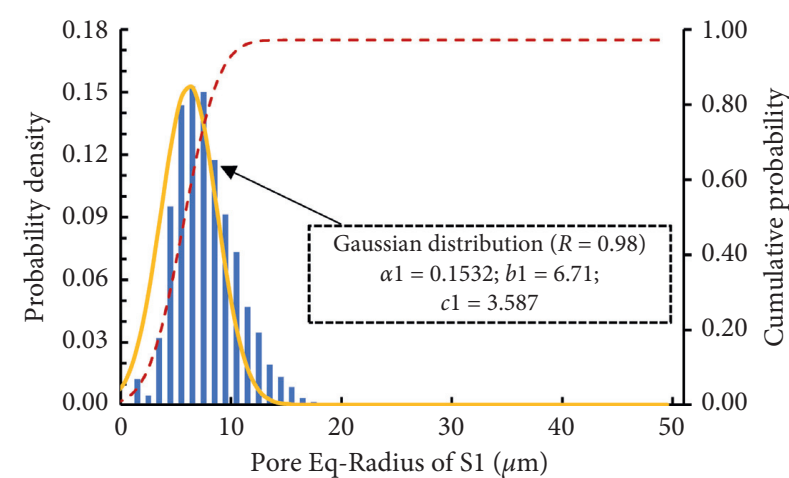

Probability density data of experiment

Probability density of fitting curve

- - - Cumulative probability curve

(b)

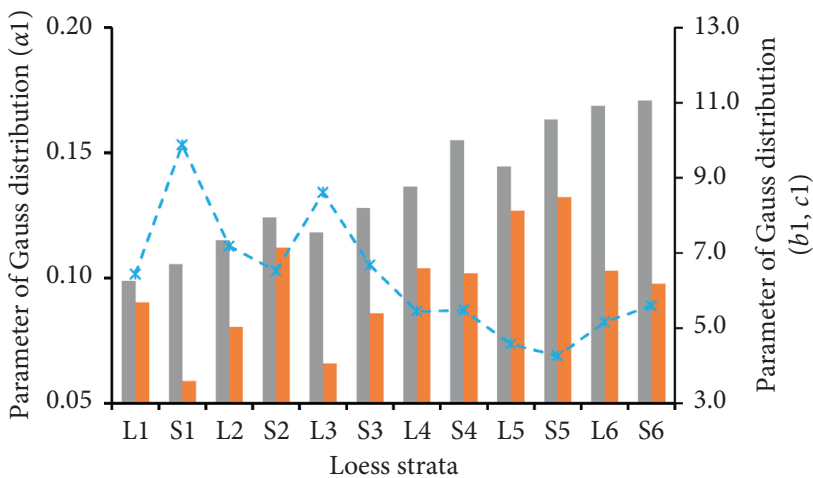

$b 1$

$c 1$

$-*-\alpha 1$

FIgURE 11: Distribution characteristics of pore Eq-Radius for loess: (a) probability density versus pore Eq-Radius of L1; (b) probability density versus pore Eq-Radius of S1; (c) distribution characteristics of pore Eq-Radius for various layers; (d) variation in fitting parameters for various layers of loess.

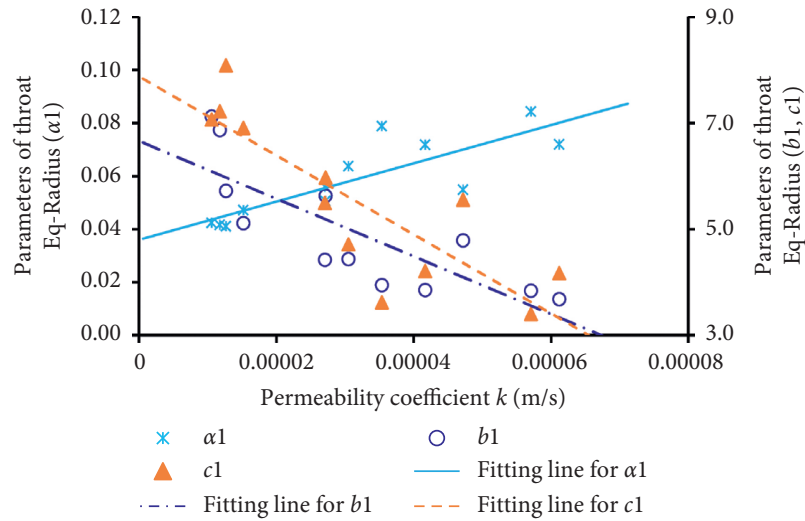

(a)

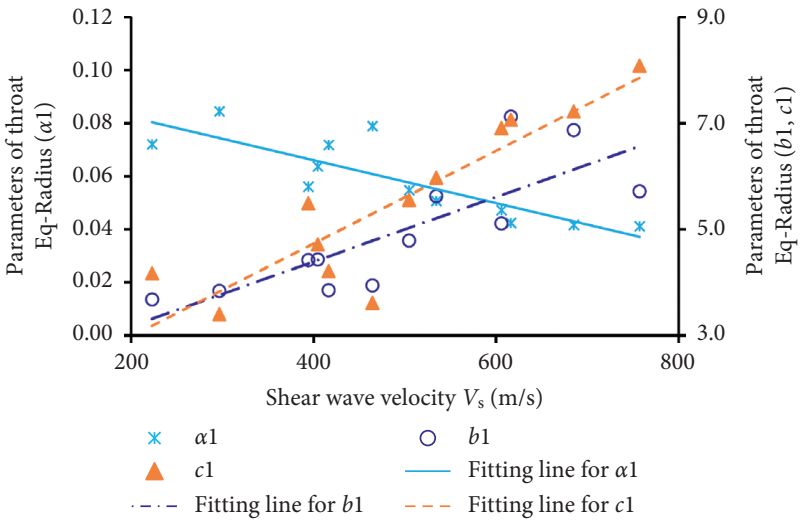

(b)

Figure 12: Continued. 

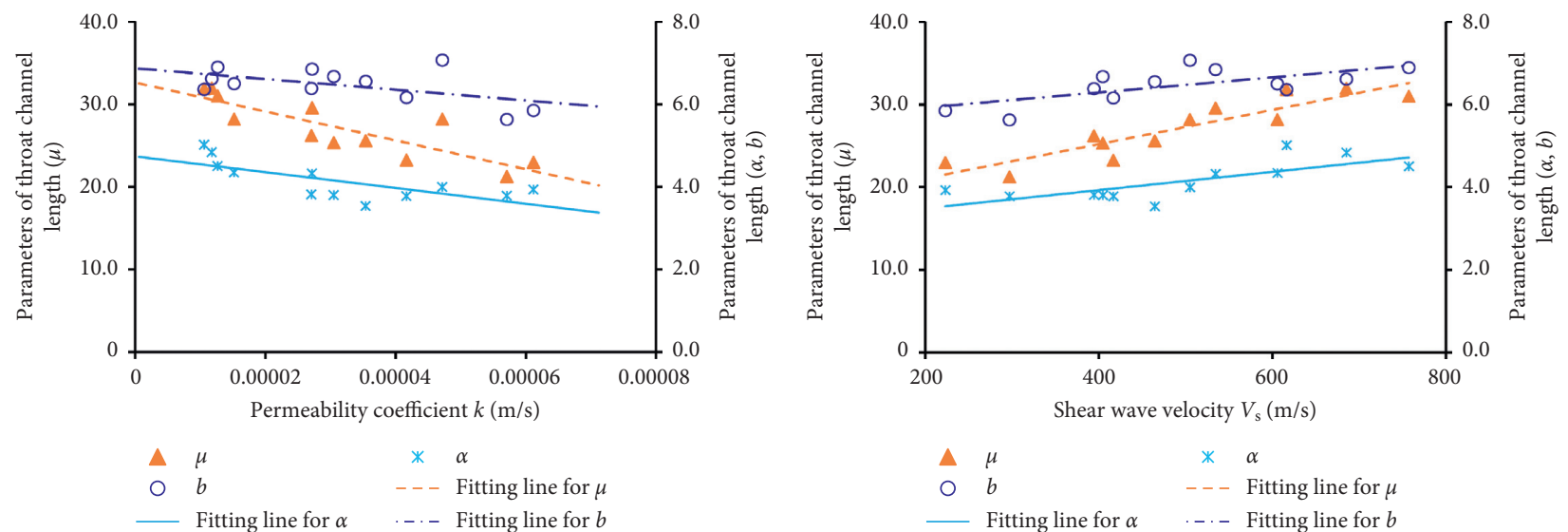

(c)

(d)

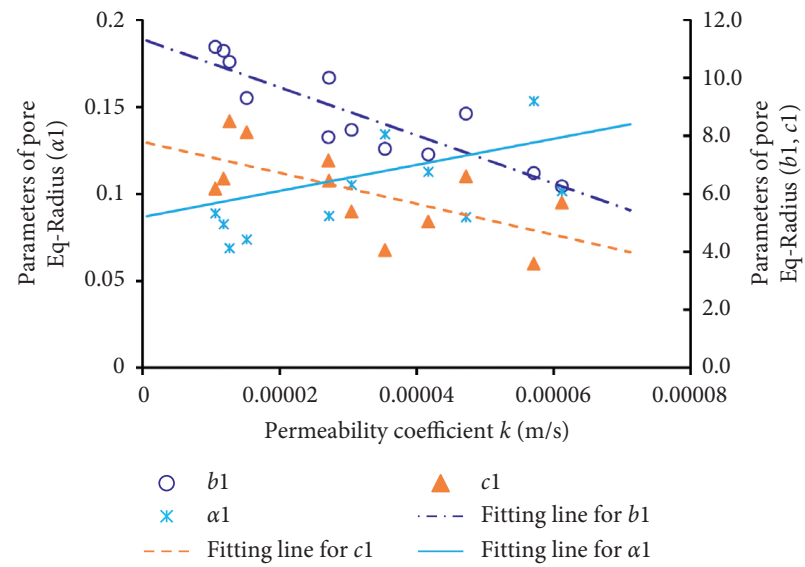

(e)

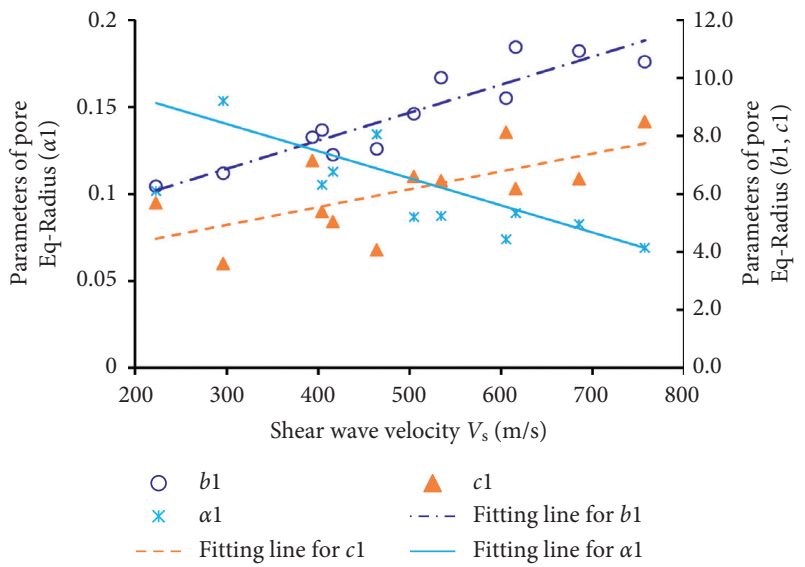

(f)

Figure 12: The relationships between the physical properties and the fitting function parameters of the loess: (a) permeability coefficient versus fitting function parameters of throat Eq-Radius; (b) shear wave velocity versus parameters of fitting function of throat Eq-Radius; (c) permeability coefficient versus coefficient of fitting function of throat channel length; (d) shear wave velocity versus fitting function coefficient of throat channel length; (e) permeability coefficient versus fitting function coefficient of throat of pore Eq-Radius; (f) shear wave velocity versus fitting function coefficient of pore Eq-Radius.

the reverse variation. Based on the above description, we propose that the macrophysical-mechanical properties of loess are quantitatively dominated by certain microstructural parameters of loess, and the quantitative correlation would be the next focus of our research. The microstructure of loess is mainly controlled by the parameters of the particles, pores, and cementation, as well as the structure model. Although the research method used in this study is available to analyze the three-dimensional quantitative characterization of particles and pores, it is difficult to investigate the cementation of particles. Consequently, the microstructurebased structure model of loess still needs to be generalized in the future.

\section{Conclusion}

The loess of the Bai Lu tableland involves a series of loesspaleosol interbedding strata, and the microstructural characteristics, physical features, and mechanical properties of this loess vary from layer to layer. As a special geotechnical material with strong structural properties, the microstructural characteristics significantly influence the macroscopic mechanical properties and catastrophic behavior of this loess. The study of the microstructure of loess contributes to a better understanding of the catastrophic behavior and physical mechanism of loess geologic hazards. The main conclusions can be summarized as follows:

(1) The volume and Eq-Radius of the loess particles satisfy a third-order Gaussian distribution, and the major-minor axis ratio of the loess particles satisfies a second-order Gaussian distribution. In the Bai Lu tableland, the loess deposited with a predominantly eastward orientation, and the directionality characteristics are more obvious for the soil in the upper layer. With increasing stratum depth, the loess particles generally become increasingly flattened.

(2) The Eq-Radius of the loess pores and throats satisfies a first-order Gaussian distribution, and the throat channel length satisfies a gamma distribution. With increasing stratum depth, the loess throat radii increase, and the pore channels become slenderer. 
(3) The fitting parameters of the distribution function obviously depend on the variation in the loess and paleosol strata, and the macrophysical-mechanical properties of the loess were controlled by certain microstructural parameters.

(4) The quantitative correlation of the microstructural parameters and the physical and mechanical properties of loess will be the focus of our future work.

\section{Conflicts of Interest}

The authors declare that they have no conflicts of interest.

\section{Acknowledgments}

This study was sponsored by the National Natural Science Foundation of China (grant nos. 41877245 and 41630634) and Open Foundation of China Railway First Survey and Design Institute Group Co., Ltd. (SPS-D-04).

\section{References}

[1] Z. Lin and W. Liang, "Engineering properties and zoning of loess and loess-like soils in China," Canadian Geotechnical Journal, vol. 19, no. 1, pp. 76-91, 1982.

[2] G. Gao, "Formation and development of the structure of collapsing loess in China," Engineering Geology, vol. 25, no. 2-4, pp. 235-245, 1988.

[3] E. Derbyshire and T. W. Mellors, "Geological and geotechnical characteristics of some loess and loessic soils from China and Britain: a comparison," Engineering Geology, vol. 25, no. 2-4, pp. 135-175, 1988.

[4] F. Zhang, R. Kong, and J. Peng, "Compositional, structural, and physicochemical properties of loess under laboratory conditions," Applied Clay Science, vol. 152, no. 1, pp. 259-266, 2018.

[5] J. Wang, P. Li, Q. Gu, Y. Xu, and T. Gu, "Changes in tensile strength and microstructure of loess due to vibration," Journal of Asian Earth Sciences, vol. 169, no. 1, pp. 298-307, 2019.

[6] F. Zhang, G. Wang, K. Toshitaka, W. Chen, D. Zhang, and J. Yang, "Undrained shear behavior of loess saturated with different concentrations of sodium chloride solution," Engineering Geology, vol. 155, no. 14, pp. 69-79, 2013.

[7] F. Zhang, G. Wang, T. Kamai, and W. Chen, "Effect of porewater chemistry on undrained shear behaviour of saturated loess," Quarterly Journal of Engineering Geology and Hydrogeology, vol. 47, no. 3, pp. 201-210, 2014.

[8] Y. Li, T. Zhang, Y. Zhang, and Q. Xu, "Geometrical appearance and spatial arrangement of structural blocks of the Malan loess in NW China: implications for the formation of loess columns," Journal of Asian Earth Sciences, vol. 158, no. 1, pp. 18-28, 2018.

[9] H. Zhu, F. Gao, and J. Pei, “Analysis of loess particles under microscope," Sciential Geological Sinica, vol. 3, no. 1, pp. 90-92, 1959, in Chinese.

[10] H. Zhu, "Some properties of particle and structure of Malan loess in middle stream of the Yellow River," Sciential Geological Sinica, vol. 2, no. 1, pp. 88-101, 1963, in Chinese.

[11] Z. Zhang, "A study on the microtexture of the Chinese loess," Acta Geologica Sinica, vol. 44, no. 1, pp. 357-366, 1964, in Chinese.
[12] J. Cegla, T. Buckley, and I. J. Smalley, "Microtextures of particles from some European loess deposits," Sedimentology, vol. 17, no. 1-2, pp. 129-134, 1971.

[13] Y. Wang and Z. Teng, "Microstructure characteristics and variation with ages and regions of loess in China," Chinese Science Bulletin, vol. 27, no. 2, pp. 102-105, 1982, in Chinese.

[14] Y. Zhang and Y. Qu, "Cements of sand loess and the ir cementation in north Shaanxi and west Shanxi," Journal of Engineering Geology, vol. 13, no. 1, pp. 18-28, 2005, in Chinese.

[15] R. G. Giménez, R. V. de la Villa, and J. A. G. Martín, "Characterization of loess in central Spain: a microstructural study," Environmental Earth Sciences, vol. 65, no. 7, pp. 2125-2137, 2012.

[16] X. A. Li and L. Li, "Quantification of the pore structures of Malan loess and the effects on loess permeability and environmental significance, Shaanxi province, China: an experimental study," Environmental Earth Sciences, vol. 76, no. 15, pp. 523-533, 2017.

[17] A. A. Velichko, T. D. Morozova, V. P. Nechaev et al., "Loess/ paleosol/cryogenic formation and structure near the northern limit of loess deposition, East European Plain, Russia," Quaternary International, vol. 152-153, no. 1, pp. 14-30, 2006.

[18] T. Gu, J. Wang, L. Guo, D. Wu, and K. Li, "Study of Q3 loess microstructure changes based on image processing," Chinese Journal of Rock Mechanics and Engineering, vol. 30, no. 1, pp. 3185-3192, 2011, in Chinese.

[19] B. G. Olszewska, "SEM analysis of microstructures of loess deposits," Bulletin of the International Association of Engineering Geology, vol. 11, no. 1, pp. 45-48, 1975.

[20] X. Lei, "Type of the loess microtextures in Xi'an district," Journal of Northwest University (Natural Science Edition), vol. 4, no. 1, pp. 34-39, 1983, in Chinese.

[21] L. Xiangyi, "The relationship between microtexture types and indices of fhysico-mechanical properties of loess in China," Acta Geologica Sinica-English Edition, vol. 2, no. 4, pp. 433443, 1989.

[22] G. Gao, "Microtexture type and collapsibility of loess soil," Science in China, vol. 12, no. 1, pp. 1203-1208, 1980, in Chinese.

[23] G. Gao, "Classification of microstructures of loess in China and their collapsibility," Scientia Sinica, vol. 24, no. 7, pp. 962-973, 1981.

[24] B. G. Olszewska, "Skeletal microstructure of loesses-its significance for engineering-geological and geotechnical studies," Applied Clay Science, vol. 4, no. 4, pp. 327-336, 1989.

[25] Z. Liu, F. Liu, F. Ma et al., "Collapsibility, composition, and microstructure of loess in China," Canadian Geotechnical Journal, vol. 53, no. 4, pp. 673-686, 2016.

[26] T. Miao, Z. Liu, and Y. Liu, "Unified catastrophic model for collapsible loess," Journal of Engineering Mechanics, vol. 128, no. 5, pp. 595-598, 2002.

[27] Q. Sun, X.-K. Zhang, and H.-E. Li, "Research on microstructural catastrophe model of deformation of collapsible loess," Rock and Soil Mechanics, vol. 29, no. 3, pp. 663-667, 2008, in Chinese.

[28] R. V. Matalucci, M. Abdel-Hady, and J. W. Shelton, "Influence of microstructure of loess on triaxial shear strength," Engineering Geology, vol. 4, no. 4, pp. 341-351, 1970.

[29] N. Wang, D. Luo, Y. Yong, X. Chen, and J. Yang, "Dynamic strength and microstructure change of Malan loess under triaxal cycle loading," Journal of Engineering Geology, vol. 19, no. 5, pp. 467-471, 2011, in Chinese. 
[30] M. Jiang, F. Zhang, H. Hu, Y. Cui, and J. Peng, "Structural characterization of natural loess and remolded loess under triaxial tests," Engineering Geology, vol. 181, no. 1, pp. 249-260, 2014.

[31] R. L. Hu, M. R. Yeung, C. F. Lee, and S. J. Wang, "Mechanical behavior and microstructural variation of loess under dynamic compaction," Engineering Geology, vol. 59, no. 3-4, pp. 203-217, 2001.

[32] J. Xia and A.-M. Han, "Cyclic variability in microstructure and physio-mechanical properties of the Xiashu Loess-palaeosol sequence in Nanjing, China," Engineering Geology, vol. 104, no. 3-4, pp. 263-268, 2009.

[33] M. Wang, Study on Structure of Collapsible Loess in China, Taiyuan University of Technology, Taiyuan, China, 2010, in Chinese.

[34] P. Li, W. Xie, R. Y. S. Pak, and S. K. Vanapalli, "Microstructural evolution of loess soils from the Loess Plateau of China," Catena, vol. 173, no. 1, pp. 276-288, 2019.

[35] L.-X. Gao, M.-T. Luan, and Q. Yang, "Evaluation of loess collapsibility based on principal components of microstructural parameters," Rock and Soil Mechanics, vol. 33, no. 7, pp. 1921-1926, 2012, in Chinese.

[36] G. Gao, "Study of the microstructures and the collapse mechanism in loess soil from Lanzhou," Journal of Lanzhou University (Natural Science Edition), vol. 1972, no. 1, pp. 1-13, 1979, in Chinese.

[37] G. Gao, "The distribution and geotechnical properties of loess soils, lateritic soils and clayey soils in China," Engineering Geology, vol. 42, no. 1, pp. 95-104, 1996.

[38] R. Li, Z. Wu, Q. Liang, S. Xu, and T. Zhao, "Influence factors of dynamic characteristics of loess considering the microstructure properties," Journal of Engineering Geology, vol. 26, no. 4, pp. 905-914, 2018, in Chinese.

[39] L.-S. Deng, W. Fan, Y.-P. Yin, and Y.-B. Cao, "Case study of a collapse investigation of loess sites covered by very thick loess-paleosol interbedded strata," International Journal of Geomechanics, vol. 18, no. 11, Article ID 05018009, 2018.

[40] F. Ma, J. Yang, and X. Bai, "Water sensitivity and microstructure of compacted loess," Transportation Geotechnics, vol. 11, no. 1, pp. 41-56, 2017.

[41] W.-l. Xie, P. Li, M.-s. Zhang, T.-e. Cheng, and Y. Wang, "Collapse behavior and microstructural evolution of loess soils from the Loess Plateau of China," Journal of Mountain Science, vol. 15, no. 8, pp. 1642-1657, 2018.

[42] W. Ni and H. Shi, "Influence of freezing thawing cycles on microstructure and shear strength of loess," Journal of Glaciology and Geocryology, vol. 36, no. 4, pp. 922-927, 2014, in Chinese.

[43] Y. Shi, L. Li, and H. Liu, "Study on the relation of loess seismic subsidence and its microstructure characters," Northwestern Seismological Journal, vol. 24, no. 2, pp. 129-134, 2002, in Chinese.

[44] Y. Shi and G. Qiu, "Constitutive relation of seismic subsidence of loess based on microstructure," Chinese Journal of Geotechnical Engineering, vol. 33, no. 1, pp. 7-11, 2011, in Chinese.

[45] S. Lei and W. Tang, "Analysis of microstructure change for loess in the process of loading and collapse with CT scanning," Chinese Journal of Rock Mechanics and Engineering, vol. 23, no. 24, pp. 4166-4169, 2004.

[46] Q. Xiao, X. Zhao, W. Lin, X. Huang, and Z. Song, “Application of NMR to test sandstone stress sensitivity of the dongfang $X$ gas field, China," IEEE Access, vol. 7, pp. 95212-95223, 2019.

[47] W. Lin, X. Li, Z. Yang, S. Xiong, Y. Luo, and X. Zhao, "Modeling of $3 \mathrm{D}$ rock porous media by combining X-ray CT and Markov chain Monte Carlo," Journal of Energy Resources Technology, vol. 142, no. 1, Article ID 013001, 8 pages, 2020.

[48] W. Lin, X. Li, Z. Yang et al., "Multiscale digital porous rock reconstruction using template matching," Water Resources Research, vol. 55, no. 8, pp. 6911-6922, 2019.

[49] Y. Lu, Reconstruction, Characterization, Modeling and Visualization of Inherent and Induced Digital Sand Microstructures, Georgia Institute of Technology, Atlanta, Georgia, 2010. 